\title{
Climate change and security
}

\author{
Paul Rogers
}

Paul Rogers

PhD DIC ARCS CBiol, Professor of Peace

Studies, Bradford

University

Clin Med

2009;9:108-9

\begin{abstract}
Climate change was originally expected to have its main impact on countries in temperate latitudes which, because of their relative wealth, would be best able to cope. It is now far more likely that much poorer states in the tropics and sub-tropics will experience severe impacts. This is compounded by the widening socioeconomic divide and the combination of these divisions, with environmental constraints, will have a profound impact on human security. The dangerous response to the prospects of mass migration and radical social movements is to attempt to maintain control without addressing underlying problems. Instead, there is an urgent need to embrace new concepts of sustainable security.
\end{abstract}

KEY WORDS: climate, migration, poverty, security, tropics

Until the early 1990s, most research into climate change indicated that the regions of the world most likely to be affected were those in the north and south temperate latitudes. While problems of rising sea level and increasingly violent weather could well be severe, at least the countries affected would be those that had strong economies and would be best able to cope. Britain, for example, might get warmer, wetter and windier but it could adapt, even if with some difficulty.

Part of the reasoning for this view was that archaeological, and other, evidence suggested that during previous instances of climate change the world's tropical and sub-tropical regions appeared to have been buffered from the main effects being experienced in the temperate latitudes. When Britain was covered in ice sheets 11,000 years ago, the climate of tropical Africa was not much different to today.

Over the last decade that view has changed and there is now a consensus that the tropical and subtropical regions of the world will be hugely affected by climate change. Sea levels will rise, the increasing intensity of tropical storms will be far more devastating than the recent hurricanes hitting New Orleans and Burma, and there will be major changes in rainfall patterns including a potential 'drying out' of some of the richest tropical croplands. ${ }^{1}$

These trends alone are serious, but they are paralleled by a global economic trend that four-fifths of the world's population is increasingly marginalised. Although the recent decades of the globalised world economy have witnessed impressive economic growth, the distribution of the resulting wealth has been extraordinarily unbalanced. Rather more than a billion people have benefited greatly but most of the rest have not. The poor are not getting poorer, but most of the world's population is not sharing in the bounty of the new wealth, and this includes a substantial majority of those in the tropical and sub-tropical regions that are going to be hit hard by climate change.

There is an added factor in that one of the impressive development successes of recent decades has been the huge improvement in education, literacy and communications across the world. While this has been greatly welcome, especially as the benefits are at last being experienced by women as well as men, one inevitable consequence has been an increasing awareness of marginalistion. People are now much more likely to know that they are being excluded from socioeconomic progress. There are many consequences of this, not least the innumerable examples of social unrest affecting many of the interior provinces of China, and the extraordinary re-birth of the neo-Maoist Naxalite rebellion that now affects almost half of all the Indian states. Another indicator is the increased pressure of migration, especially into Europe and North America, as people desperately seek a better life.

These are trends that are already underway, but they will be hugely exacerbated unless climate change is controlled. The great risk is that climate change will be seen more and more as a security issue for the elite communities of the world, with a strong tendency to 'close the castle gates' rather than address the core issues of socioeconomic divisions and environmental constraints.

Thirty-five years ago the economic geographer Edwin Brooks wrote of the risk of a 'crowded glowering planet of massive inequalities of wealth, buttressed by [a] stark force yet endlessly threatened by desperate people in the global ghettoes'. ${ }^{2}$ There is a strong echo of those words in the heavily protected gated communities in many cities, or the bodies of would-be migrants from North Africa washed up on the Mediterranean shores of Europe.

It is common for military thinktanks to 'securitise' climate change as they seek to preserve the security of their own societies, but this is both blinkered and 
inadequate. One of the implications of the September 112001 attacks and the consequent problems of the war on terror is a failure to recognise that modern advanced societies are hugely vulnerable to radical social movements that may be increasingly driven to extreme actions by desperation, anger and bitterness. ${ }^{3}$

The current western approach to international security is best described as the 'control paradigm' that seeks to maintain control rather than address the underlying problems. Global challenges demand global responses rooted in sustainable security. ${ }^{4}$ This involves concerted and persistent policies to reverse socioeconomic divisions with urgent action to prevent the excesses of climate change and increased aid to the weaker societies that are unable to cope with those aspects of climate change that are already inevitable.

\section{References}

1 Rind D. Drying out the tropics. New Scientist, 6 May 1995.

2 Brooks E. The implications of ecological limits to growth in terms of expectations and aspirations in developed and less developed countries. In: Vann A, Rogers P (eds), Human ecology and world development. New York: Plenum Press, 1974.

3 Rogers P. Losing control: global security in the 21st century. London: Pluto Press, 2002.

4 Oxford Research Group. Global responses to global challenges. Oxford: ORG, 2006. 